\title{
Projeto de Iniciação Científica: uma proposta de processo*
}

\section{Scientific initiation project: a process proposal}

José Gladistone da Rocha Carlo Kleber da Silva Rodrigues ${ }^{2}$
* Recebido em: 09/04/2016. Aprovado em: 10/12/2016.

1 Mestre em Ciências Militares pela Escola de Aperfeiçoamento de Oficiais do Exército (EsAO) (1994). Bacharel em Ciências Militares pela Academia Militar das Agulhas Negras (AMAN) (1985). Bacharel em Sistemas de Informação pelo Centro Universitário do Sul de Minas (UNIS) (2014). Pós-Graduado em Análise de Sistemas pelo Centro de Estudos de Pessoal do Exército; Pós-Graduado em Criptografia e Segurança em Redes de Computadores pela Universidade Federal Fluminense (UFF) e Pós-Graduado em Docência do Ensino Superior, pela Universidade Castelo Branco (UCB).

2 Doutor em Engenharia de Sistemas e Computação pela Universidade Federal do Rio de Janeiro (UFRJ, 2006). Mestre em Sistemas e Computação pelo Instituto Militar de Engenharia (IME, 2000). Graduado em Engenharia Elétrica (Eletrônica e Eletrotécnica) pela Universidade Federal de Campina Grande (UFCG, 1993). Professor do Centro Universitário de Brasília (UniCEUB) nos cursos de Ciência da Computação e Engenharia de Computação.

\section{Resumo}

Há poucos trabalhos na literatura que tratam, de forma detalhada, as ações a serem executadas em projetos de Iniciação científica em Instituições de Ensino Superior. Diante dessa realidade, este trabalho tem por objetivo apresentar uma proposta de processo para execução de projetos dessa natureza em cursos de nível superior de tecnologia em computação. A contribuição advinda dessa proposta é, principalmente, proporcionar aos orientadores um guia geral para a condução eficiente e segura do trabalho de pesquisa juntamente aos seus orientandos, assegurando, principalmente, a consecução das metas estabelecidas para a pesquisa. Para tanto, são analisados trabalhos anteriores da literatura, observada a experiência dos autores deste trabalho na condução prática de projetos dessa natureza e, por fim, realizadas entrevistas com graduandos de diferentes Instituições de Ensino Superior da cidade de Brasília, Distrito Federal.

Palavras-chave: Ensino Superior. Iniciação Científica. Modelo. Processo.

\section{Abstract}

There are few studies in the literature that deal in detail with the procedures to be carried out during the execution of Scientific Initiation Projects in Higher-Education Institutions. Given this reality, this work aims to present a proposal for the execution process of such projects, specifically focusing on higher-education courses in the field of computer and science technology. The arising contribution of this proposal is mainly to provide a general guide for the execution of a quite safe and efficient research project, thereby ensuring the achievement of the goals which are initially set for the research. To this end, previous works of the literature, the field experience of these authors, and interviews with graduates belonging to distinct higher-education institutions of the city of Brasília are altogether considered.

Keywords: Higher Education. Scientific Initiation. Model. Process. 


\section{Introdução}

O desenvolvimento das atividades que envolvem um Projeto de Iniciação Científica (PIC) se reveste de características peculiares que se diferem da rotina de estudo de disciplinas regulares de cursos oferecidos em Instituições de Ensino Superior (IES).

A Iniciação Científica (IC) é entendida como um instrumento que permite introduzir os estudantes de graduação nos caminhos da pesquisa científica (MARCUSHI, 1996). Para o CNPq (BRASIL, 2015a), a IC trata-se de um instrumento básico de formação, que tem em perspectiva o treinamento em metodologia científica, o desenvolvimento da análise e do julgamento crítico, e o incentivo à criatividade e à inovação (MAZON; TREVIZAN, 2001; MARCUSCHI, 1996; BRASIL, 2015a).

É verdade que o Ministério da Educação (MEC) (BRASIL, 2015a; BRASIL, 2015b) estimula, por meio de concessão de bolsas de estudo aos alunos, a prática de IC. Esse incentivo, no entanto, não é ainda suficiente para absorver o público das IES privadas (OLIVEIRA, 2001; MARCUSCHI, 1996). Além disso, o que se percebe é que, tanto no meio docente como no discente, a atividade de pesquisa científica, particularmente em IES privadas, não é bem conhecida quanto à sua condução (SOUSA; MARQUES, 2011; NEUENFELDT et al., 2011; GATES et al., 1998), e os benefícios aos graduandos e orientadores não são bem evidenciados (GATES et al., 1998).

A literatura, por sua vez, traz poucos estudos (MARCUSCHI, 1996; COSTA, 2013) que envolvem a execução detalhada de PIC, restringindo-se, na maioria das vezes, a relatos de princípios básicos a serem seguidos (CARTONI, 2009b; GATES et al., 1998). Na grade de disciplinas dos cursos, o assunto é, apenas, explorado em matérias de Metodologia Científica, ou de denominações similares, que tratam do pensamento científico (OLIVEIRA, 2001), porém, sem haver um direcionamento prático para a sua execução (NEUENFELDT et al., 2011).

Acrescenta-se, também, que não há, ainda, soluções contundentes para alguns dos problemas relacionados à realização de IC como a dificuldade dos graduandos em conciliar as atividades da pesquisa com as disciplinas de curso, o acompanhamento inadequado por parte dos orientadores, e a restrição de bolsas de estudo para execução dos PICs (CARTONI, 2009a; MORAES; FAVA, 2000; SOUSA; MARQUES, 2011; OLIVEIRA, 2001; SILVA JU-
Ante o exposto, este artigo visa apresentar uma proposta de Processo de Execução de Projeto de Iniciação Científica (PEPIC) para cursos de tecnologia em computação de IES privadas. O modelo do processo, a definição e o detalhamento de todas as ações a serem executadas em um PIC são aqui apresentados. Além disso, são destacadas as fases que promovem maior integração entre graduandos e orientadores participantes de PIC, ressaltando aspectos relacionados à interação humana, considerado como fator primordial ao sucesso desses projetos nas IES (MACCARIELLO et al., 2002).

A contribuição advinda dessa proposta é, principalmente, proporcionar aos orientadores das IES um guia geral para condução eficiente e segura do trabalho de pesquisa juntamente aos seus orientandos, assegurando a consecução das metas estabelecidas para a pesquisa. Para tanto, são analisados trabalhos anteriores da literatura, observada a experiência práticas dos autores deste trabalho na condução de PIC e, por fim, realizadas entrevistas com graduandos de diferentes IES na cidade de Brasília, Distrito Federal.

Por fim, o restante deste texto está estruturado da seguinte forma: a Seção 2 discute sobre a principal e mais recente literatura que trata do assunto; a Seção 3 discorre sobre a metodologia utilizada para coleta de dados para a realização da proposta deste artigo; a Seção 4 apresenta o modelo e as fases do processo proposto para a execução de PIC e, finalmente, a Seção 5 apresenta as conclusões finais e os direcionamentos para trabalhos futuros.

\section{Trabalhos relacionados}

Mazon e Trevisan (2001) apresentam suas experiências em PIC ao adotarem uma abordagem de interdisciplinaridade na condução dos trabalhos, ou seja, a adoção perceptiva do pesquisador de IC sob diferentes enfoques, em que, ao abarcar um fenômeno, este deve ser estudado por vários e diferentes ramos do conhecimento.

Oliveira (2001) retrata que a educação científica adotada nas IES, via de regra, aborda duas linhas distintas: a dos filósofos da ciência e a dos estudiosos do processo de aquisição do conhecimento das teorias de aprendizagem. Tais abordagens são desacompanhadas de exercícios práticos pelos alunos das teorias apresentadas. $\mathrm{O}$ autor, ainda, ressalta a importância da produção intelectual dos docentes, como formação continuada do professor pesquisador, para que, lentamente, não se desaprenda a atitude científica que é necessária para a condução de orientações em PIC. 
Segundo Massi e Queiroz (2010), poucos professores das IES privadas se dedicam à pesquisa em virtude da característica da universidade e do regime de trabalho. As autoras retratam que o desenvolvimento do trabalho de pesquisa é determinado, quase que, exclusivamente, pelo orientador, o que resulta, principalmente, em diferentes formas de condução da pesquisa e de seleção dos alunos bolsistas de IC.

Por sua vez, Souza e Marques (2011) ressaltam a necessidade de existir um relacionamento harmônico e construtivo, entre alunos bolsistas de IC e seus orientadores, pois isso minimiza possíveis desestímulos aos alunos no prosseguimento dos trabalhos de pesquisa em IC. Os autores retratam, ainda, que há programas e atividades de IC que se tratam de mera execução, sem a preocupação mínima com a promoção e construção do conhecimento.

Lordelo et al. (2011) abordam o exercício da IC na graduação como instrumento eficaz na ascensão ao mestrado para diversas áreas do conhecimento. Em sua pesquisa, na Universidade Federal da Bahia (UFBA), os autores constataram que, em média, a predição da IC, como elemento para ingresso no mestrado, foi de 53,4\% dos graduados que realizaram PIC na formação acadêmica. Isso demonstra a relevância da atividade de IC na graduação.

Por fim, Costa (2013), em sua pesquisa de mestrado, analisou o destino de egressos de PIC da Universidade Federal de Santa Catarina (UFSC), no período de 1990 a 2012, e constatou que 50,19\% destes atingiram a titulação de mestrado ou superior.

\section{Metodologia de coleta de dados}

Neste trabalho é utilizado o método indutivo (WIKIPÉDIA, 2015) para ordenar a formação do raciocínio, uma vez que são utilizados dados existentes em obras constantes na literatura para, por meio de uma análise, se chegar a argumentações embasadas que se alinham ao objetivo deste artigo, ou seja, a apresentação de uma proposta de PEPIC para condução das atividades de PIC nas IES privadas.

O PEPIC proposto é baseado, também, em experiências práticas colhidas por esses autores durante a execução de 16 PICs, envolvendo 16 graduandos dos cursos de Engenharia da Computação, Ciência da Computação e Sistema de Informações, realizados no período de 2010 a 2016, em duas IES privadas de Brasília, DF.

Por fim, também, são realizadas entrevistas semiestruturadas (MANZINI, 2012), com aplicação de questionário em três IES privadas de Brasília-DF, no período de 2015 e 2016, entre 112 graduandos do $2^{\circ}$ ao $8^{\circ}$ período dos cursos de Engenharia de Computação, Ciência da Computação e Sistemas de Informações, cujo objetivo é identificar o cenário de execução de IC nas IES privadas de Brasília, DF. A aplicação do questionário é realizada, diretamente, nas salas de aulas dos graduandos. O questionário contém 11 perguntas, sendo 9 fechadas e 2 abertas, direcionadas ao conhecimento de IC e às características de sua execução pelos alunos das IES envolvidas.

\section{Proposta de PEPIC}

Explica-se que a preparação visual dos diagramas componentes do PEPIC proposto baseia-se em técnicas de Business Process Model and Notation (BPMN) (OMG, 2011). Os diagramas construídos apresentam os papéis envolvidos, as atividades a serem realizadas e sua sequência de desencadeamento ou fluxos de trabalho.

Ainda, o PEPIC proposto é dividido em três fases distintas, sendo cada fase constituída de um processo principal. Apenas para apresentar uma visão geral inicial, a Figura 1 traz o PEPIC como um todo, explicitando as três fases por meio dos três processos constituintes correspondentes, indicados com sinal de adição $(+)$.

Figura 1: Processo PIC - Visão Geral

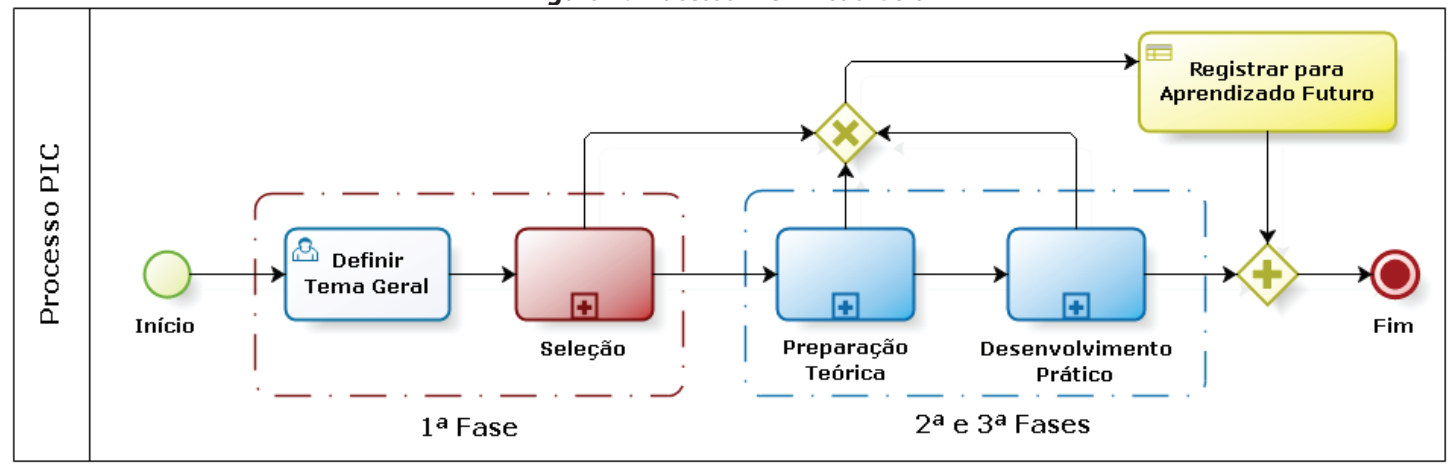

Fonte: os autores. 
Por fim, o restante desta Seção está dividido em três Subseções. A Subseção 4.1 analisa os dados coletados a partir das entrevistas semiestruturadas, explicadas anteriormente. A Subseção 4.2 descreve as fases que compõe o PEPIC. Por fim, a Subseção 4.3 define abordagens para sua implantação em IES privadas.

\subsection{Análise dos resultados das entrevistas}

Após a realização das entrevistas, os dados obti- dos são tabulados para análise e conclusões. Conforme a Figura 2(a), mais da metade dos alunos entrevistados, $56 \%$, afirmam desconhecer o que é IC, o que é bem significativo. Em relação aos 38\% que afirmam conhecer IC, $41 \%$ dizem que desconhecem as vantagens de participar de um PIC, conforme a Figura 3(b). Isso, provavelmente, pode ser uma das causas de a grande maioria, 91\% não ter participado de PIC nas IES, conforme indicado na Figura 2(c).

Figura 2: Conhecimento e divulgação de IC nas IES

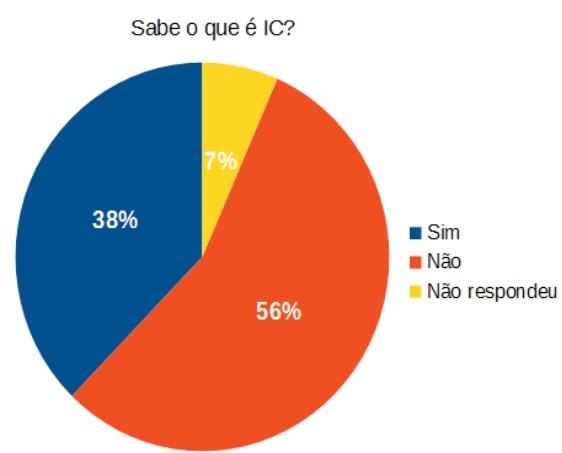

(a)

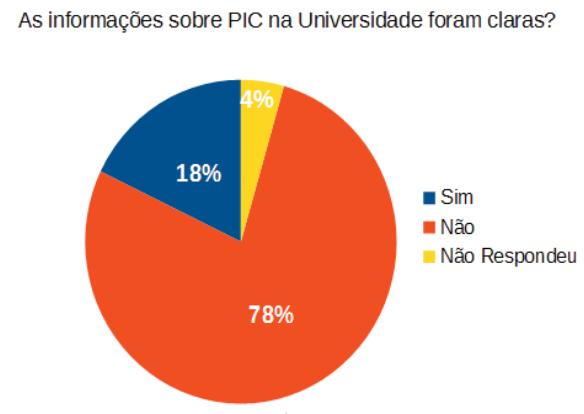

(b)

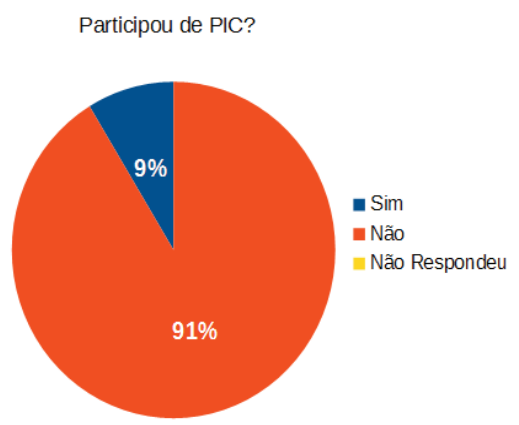

(c)

Fonte: os autores.

Figura 3: Alunos que responderam conhecer IC

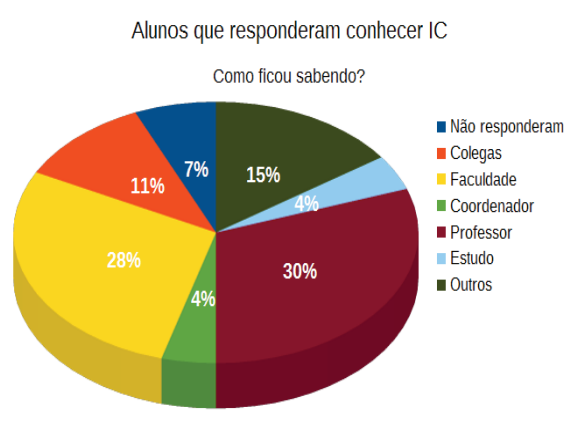

(a)

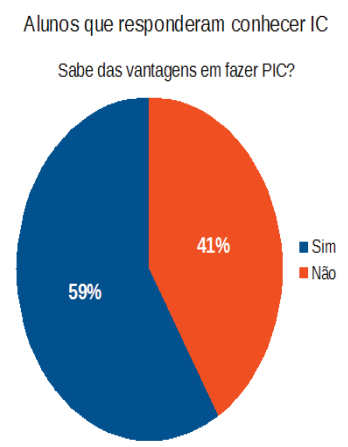

(b)

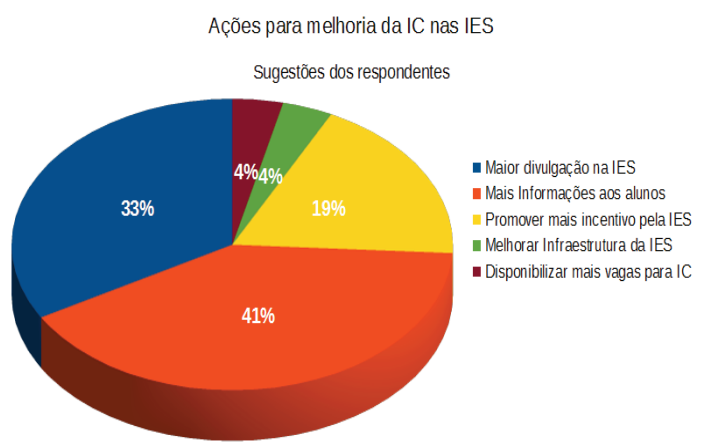

(c)

Fonte: os autores.

Os $38 \%$ dos alunos que afirmam ter conhecimento de IC, conforme a Figura 2(a), informam que a maior fonte desse conhecimento é oriunda, basicamente, de: professores (30\%), sites da faculdade (28\%) e outros meios (15\%), conforme Figura 3(a). Além disso, a grande maioria dos entrevistados, $78 \%$, afirmam que a divulgação dessa atividade nas IES é pouco esclarecedora, conforme a Figura 2(b). Isso indica a necessidade de divulgação do assunto de forma mais detalhada nas IES.
Por fim, os alunos, ainda, sugerem algumas melhorias que podem ser implementadas no processo das IES, conforme a Figura 3(c), em que a maior divulgação e mais informações esclarecedoras sobre o assunto são sugestões de 74\% dos respondentes.

\subsection{Fases do processo}

Como já mencionado, o PEPIC proposto está estruturado em três fases distintas. A primeira fase 
refere-se à seleção dos alunos candidatos ao PIC. Seu principal objetivo é identificar os alunos interessados em realizar um PIC, verificar suas aptidões, e selecionar os projetos mais adequados para realização de um trabalho de IC.

A segunda e terceira fases do processo referem-se à execução do PEPIC. A segunda fase envolve o estudo teórico dos assuntos pelos alunos, e a terceira fase abrange a execução prática dos assuntos abordados na fase anterior. Detalhes de cada fase são apresentados nas subseções seguintes deste texto.

A Figura 4 apresenta alguns dados numéricos na execução do PEPIC proposto, incluindo-se o tempo médio destinado a cada fase e o número médio de Artigos Científicos (ACs) a serem estudados, segundo a experiência usualmente vivenciada pelos orientadores nas IES consideradas nesta pesquisa. Para todo o projeto, o aluno deve disponibilizar uma carga horária de 20 horas por semana para dedicação aos trabalhos de PIC, incluindo-se aí os encontros com seu orientador para discussão dos assuntos. O processamento (leitura) de $01 \mathrm{AC}$ a cada 15 horas é o desejável.

Figura 4: Dados numéricos para execução do PEPIC proposto

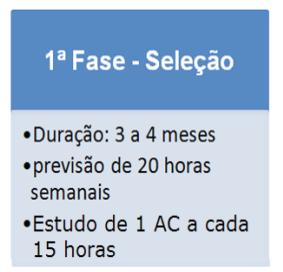

Fonte: os autores.
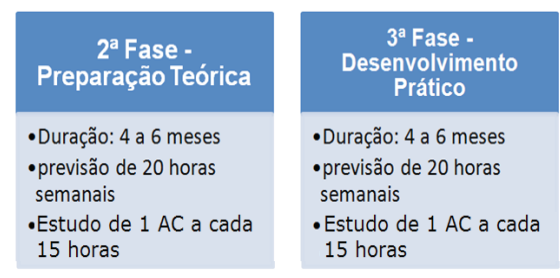

É oportuno apresentar quais atores estão envolvidos no processo e quais papéis são exercidos. O Quadro 1 apresenta, resumidamente, tais informações. Entende-se por ator cada pessoa que executa parte ou todo o processo, visando a possibilitar que se atinjam os objetivos do processo (OMG, 2011), e por papéis as funções ou encargos a serem desempenhados pelos atores (OMG, 2011).

Quadro 1: Atores do PEPIC. Fonte: os autores

\begin{tabular}{|l|l|}
\hline \multicolumn{1}{|c|}{ Ator } & \multicolumn{1}{c|}{ Papel } \\
\hline Coordenador de PIC & $\begin{array}{l}\text { Professor que coordena as atividades de PIC na instituição com definição de temas de trabalhos, segundo as linhas de pesquisas adotadas pela IES. Encaminha à } \\
\text { direção os projetos recebidos para aprovação conforme as bolsas disponibilizadas. }\end{array}$ \\
\hline Orientador & $\begin{array}{l}\text { Professor, com titulação de mestre ou superior, responsável pela pré-seleção dos projetos dos alunos candidatos. Supervisiona as atividades executadas pelos seus } \\
\text { orientandos, em que exerce forte influência ao motivá-los na continuidade dos trabalhos e no endereçamento de soluções de impasses nos projetos. São correspon- } \\
\text { sáveis pela qualidade científica e ética das atividades de pesquisa de seus orientandos, bem como dos relatos de seus resultados (FAPESP, 2012). }\end{array}$ \\
\hline Aluno Candidato & $\begin{array}{l}\text { Aluno que se enquadra nos pré-requisitos definidos pela IES para atuar em PIC. Participa da primeira fase do processo PIC, com a construção da proposta de PIC a ser } \\
\text { submetida ao Orientador para aprovação e posterior submissão à Coordenação de PIC da IES. }\end{array}$ \\
\hline Aluno de PIC & $\begin{array}{l}\text { Aluno com projeto aprovado pelo Coordenador de PIC da IES e responsável pela execução de todas as atividades até sua conclusão. Realiza atividades administrativas } \\
\text { inerentes a seu projeto com a geração de relatórios parciais do seu projeto de IC. }\end{array}$ \\
\hline
\end{tabular}

Fonte: Dos Autores

Para execução do PIC, presume-se que a IES possui linhas de pesquisas definidas para realização de IC, conforme interesse da IES. Por isso, consta, no modelo da Figura 1, a atividade Definir Tema Geral como uma fonte alimentadora de todo o processo, envolvendo o ator Coordenador de PIC.

\subsubsection{Primeira fase - Seleção}

Normalmente, há restrições quanto ao número de projetos a serem aceitos pelas IES em face das disponibilidades limitadas de bolsas de pesquisa, número de professores orientadores, e quantidade de projetos que cada orientador pode supervisionar. Assim, essa fase se torna importante para que a execução das demais fases do PIC tenha êxito.

A IES, ao implantar e divulgar esse PEPIC proposto, tende a ter a ampliação do número de alunos candidatos interessados na realização de PICs, comparativamente a um cenário sem divulgação alguma. $\mathrm{O}$ aumento desse universo possibilita à instituição, por intermédio dos orientadores, selecionar mais criteriosamente os alunos com maior controle emocional, disposição para estudo, valor intelectual, e tempo disponível.

Nessa fase é realizada uma ambientação entre os candidatos com a exposição, de forma geral, da caracterização de um PIC e as atividades a serem executadas ao 
longo do projeto. A Figura 5 apresenta as atividades envolvidas nessa fase, os atores envolvidos e o fluxo de trabalho a ser executado.

Figura 5: Atividades integrantes da fase de seleção do PEPIC

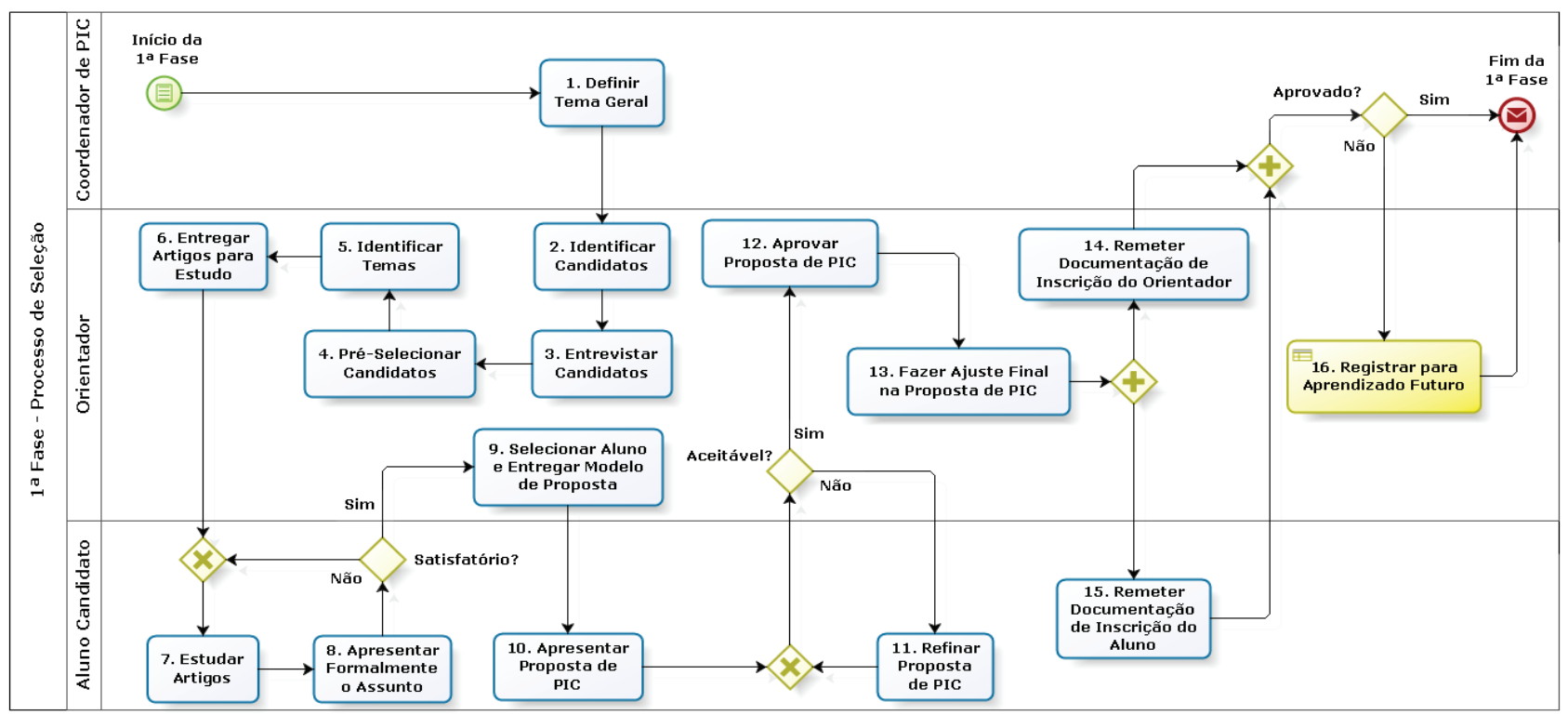

Fonte: os autores.

Nessa fase há, também, uma grande interação entre Orientador e Aluno Candidato para que a seleção seja eficiente, tanto em número quanto em qualidade de propostas de projetos, possibilitando o devido preenchimento das vagas de acordo com a capacidade de absorção de projetos pelos orientadores (MACCARIELLO et al., 2002).

O Quadro 2 apresenta os objetivos de cada uma das atividades da Fase de Seleção e as peculiaridades que devem ser consideradas na sua execução. Os números indicados no quadro referem-se às atividades apresentadas na Figura 5.

Quadro 2: Caracterização das atividades da fase de seleção. Fonte: os autores

\begin{tabular}{|c|c|}
\hline No & Objetivos e Peculiaridades \\
\hline 1 & $\begin{array}{l}\text { Objetivos: Definir temas gerais para PIC nas áreas de conhecimento de interesse da IES. } \\
\text { Peculiaridades: Os temas podem ser modificados anualmente. }\end{array}$ \\
\hline 2 & $\begin{array}{l}\text { Objetivos: Relacionar os candidatos ao processo seletivo. } \\
\text { Peculiaridades: } 0 \text { Orientador deve definir datas para entrevistas e coletas de informaçōes. }\end{array}$ \\
\hline 3 & $\begin{array}{l}\text { Objetivos: Entrevistar os alunos candidatos para identificar seus perfis e potencialidades. Relatar sumariamente como se dará o processo. } \\
\text { Peculiaridades: } 0 \text { Orientador apresenta aos alunos as vantagens e dificuldades na participação de um PIC. Ainda, ressalta a importância da dedicação na execução do processo. } \\
\text { Normalmente, orientadores mais experientes conseguem persuadir aqueles sem têm real interesse, para dar chance àqueles que realmente desejam encarar um trabalho profícuo, } \\
\text { pois as vagas são limitadas. }\end{array}$ \\
\hline 4 & $\begin{array}{l}\text { Objetivos: Pré-selecionar os alunos que prosseguirão na fase de seleção com base nas entrevistas dos alunos candidatos. } \\
\text { Peculiaridades: Trata-se de uma triagem inicial dos candidatos para escolha, pelo Orientador, dos alunos que prosseguirão na fase de seleção. Fruto de limitações do Orientador há } \\
\text { necessidade de uma escolha criteriosa dos candidatos a realizarem o PIC. Escolhas malsucedidas poderão resultar em desistência do aluno no meio do processo. } \\
\text { Sugere-se a seleção de um percentual de alunos maior do que a capacidade pretendida pelo Orientador em supervisionar trabalhos de PIC. Como exemplo, se o Orientador pretende } \\
\text { trabalhar com dois alunos, a seleção de três ou quatro alunos é adequada para continuarem na fase de pré-seleção. Todos os alunos devem ter ciência disso, para que haja empenho } \\
\text { deles e para que a seleção seja justa e transparente. }\end{array}$ \\
\hline 5 & $\begin{array}{l}\text { Objetivos: Definir temas, pelos alunos pré-selecionados, alinhados com a linha de pesquisa traçada ou tema geral proposto pela IES e, se possível, à linha de pesquisa do Orientador. } \\
\text { Peculiaridades: } 0 \text { Orientador deve verificar se os temas propostos atendem a esse objetivo. Ajustes, normalmente, são realizados, pelo Orientador, de forma a adequar os temas } \\
\text { propostos. }\end{array}$ \\
\hline 6 & $\begin{array}{l}\text { Objetivos: Pesquisar na literatura Artigos Científicos relacionados com cada tema a ser trabalhado na IC. } \\
\text { Peculiaridades: } 0 \text { Orientador deve selecionar para cada tema três AC, preferencialmente mais atualizados e na língua inglesa, visando mais adiante à preparação da Proposta de } \\
\text { Pesquisa. Sugere-se a entrega de forma sequencial na medida em que o aluno apresente os resultados esperados de cada um deles. }\end{array}$ \\
\hline 7 & $\begin{array}{l}\text { Objetivos: Estudar o AC visando identificar pontos importantes que agreguem valor ao trabalho que irá realizar. Forçar o aluno quanto a sua proficiência na leitura em língua inglesa. } \\
\text { Peculiaridades: Isso permite ao Aluno candidato travar contato com outros trabalhos já realizados para familiarizar-se com sua abordagem. } 0 \text { estudo visa, ao aluno, dar sustentação } \\
\text { teórica ao que pretende pesquisar. Esse estudo é consubstanciado em um resumo escrito, do material estudado, e serve como fichamento (CARTONI, 2009a) para uso na segunda fase } \\
\text { do processo PIC. }\end{array}$ \\
\hline
\end{tabular}




\begin{tabular}{|c|c|}
\hline 8 & $\begin{array}{l}\text { Objetivos: Treinar o Aluno em exposiç̃eses de assuntos e apresentação formal ao Orientador. } \\
\text { Peculiaridades: } 0 \text { Orientador que fará sua apreciação sobre o material apresentado. Caso não tenha uma boa qualidade, fará suas observações visando ajustes pelo Aluno. Esses } \\
\text { encontros são um excelente exercício para que o aluno apresente, nos próximos resumos, materiais mais focados ao tema proposto no projeto. } \\
\text { Destaca-se que essa atividade, pelo seu grau de importância, não deve ser levada a segundo plano, quanto a sua execução, pois é considerada como ponto chave de toda a fase de } \\
\text { seleção e onde realmente se observa a capacidade de pronta resposta do aluno, quanto ao que pretende. }\end{array}$ \\
\hline 9 & $\begin{array}{l}\text { Objetivos: Fazer uma análise crítica de diversos fatores como qualidade dos resumos apresentados, disponibilidade e interesse dos alunos, e outros aspectos subjetivos que interferem } \\
\text { num trabalho de IC. Selecionar, dentre os alunos candidatos, aqueles que têm melhores condiçôes de execução de um PIC. } \\
\text { Peculiaridades: Nessa altura do processo, o Orientador terá boas condições para definir, dentre os candidatos, aqueles que terão melhores condiçōes para execução de um PIC. Alguns } \\
\text { aspectos que podem ser observados nos alunos e considerados para sua decisão são: facilidade na interpretação dos artigos, qualidade na escrita dos resumos, objetividade, dedica- } \\
\text { ção, facilidade de argumentação escrita e verbal, dentre outros que considere pertinente. } \\
\text { Essa etapa da seleção é concluída com a entrega, pelo Orientador, do Modelo de Proposta de PIC a ser preenchida pelo Aluno selecionado, com base em seu tema de pesquisa. } \\
\text { Eventualmente, o próprio Aluno selecionado poderá obter esse e outros modelos, referentes ao PIC, no site da IES. }\end{array}$ \\
\hline 10 & $\begin{array}{l}\text { Objetivos: Analisar a Proposta de PIC do Aluno para verificar sua adequaçãa, completeza e detalhes relevantes, que, possivelmente, possam ser melhorados visando sua aprovação } \\
\text { final para encaminhamento ao Coordenador de PIC da IES. } \\
\text { Peculiaridades: } 0 \text { Aluno selecionado deverá preencher a Proposta de PIC e apresentar ao Orientador, para fins de apreciação e/ou ajustes. A apreciação da Proposta de PIC, pelo } \\
\text { Orientador, incidirá em uma das direções a seguir: reformulação ou aprovação da proposta. }\end{array}$ \\
\hline 11 & $\begin{array}{l}\text { Objetivos: Fazer ajustes de forma a atender às sugestões do Orientador para tornar a Proposta de PIC em condições de aprovação pelo Orientador e dar encaminhamento ao Comitê de } \\
\text { PIC da IES. } \\
\text { Peculiaridades: Caso o Orientador indique que a Proposta de PIC deva ser reformulada, o aluno deverá fazer ajustes convenientes de forma a atender às sugestões de correções do } \\
\text { Orientador. } 0 \text { processo retorna à atividade } 10 \text { para que a Proposta de PIC seja reavaliada pelo Orientador. }\end{array}$ \\
\hline 12 & $\begin{array}{l}\text { Objetivos: Analisar a Proposta de PIC refinada e aprovar formalmente perante o aluno proponente. } \\
\text { Peculiaridades: Quando o Orientador perceber que a Proposta de PIC esteja com conteúdo aceitável, dará sua aprovação formal ao Aluno para que ele dê prosseguimento ao processo } \\
\text { de submissão da proposta ao Comitê de IC da IES. }\end{array}$ \\
\hline 13 & $\begin{array}{l}\text { Objetivos: Fazer uma revisão final da Proposta de PIC para que esteja em condições de ser aprovada pela Coordenação de PIC da IES. } \\
\text { Peculiaridades: Essa atividade é executada quanto ao Orientador perceber que, mesmo após sua aprovação da Proposta de PIC, devam ser realizados alguns ajustes finais para } \\
\text { proporcionar maiores chances de aprovação pela Coordenação de IC da IES. } \\
\text { Outra medida administrativa é a preparação da documentação referente ao Orientador e ao Aluno interessado. Essas açōes finais dependem, efetivamente, da legislação da IES } \\
\text { quanto a esse processo de aprovação. }\end{array}$ \\
\hline 14 & $\begin{array}{l}\text { Objetivos: Preencher dados profissionais do Orientador em fichas de informações da IES. } \\
\text { Peculiaridades: } 0 \text { Orientador deverá preencher fichamentos com suas informações que deverá completar, com a do aluno, o processo de submissão da proposta do aluno junto a IES. }\end{array}$ \\
\hline 15 & $\begin{array}{l}\text { Objetivos: Preencher dados do Aluno solicitados pelas fichas de informações da IES. } \\
\text { Peculiaridades: } 0 \text { Aluno deverá preencher fichamentos com suas informaçōes que completará com a do seu Orientador, o processo de submissão da sua proposta, junto a IES. }\end{array}$ \\
\hline 16 & $\begin{array}{l}\text { Objetivos: Registrar pontos observados pelo Comitê de PIC da IES que levaram à reprovação da Proposta de PIC do aluno para servir como liçōes aprendidas para uso em trabalhos futuros. } \\
\text { Peculiaridades: } 0 \text { Orientador registrará, em um banco de lições aprendidas, os pontos que não foram atendidos e que motivaram a reprovação da proposta. Isso o auxiliará, futura- } \\
\text { mente, a refinar seu processo de abordagem na Fase de Seleção para aplicação nas Propostas de PIC de anos posteriores. }\end{array}$ \\
\hline
\end{tabular}

Fonte: Dos Autores

Após a execução da Fase de Seleção, é necessária a entrega formal das propostas de PIC junto à Coordenação de Iniciação Científica da IES, que emite pareceres de aprovação ou reprovação, concluindo-se, assim, a fase de Seleção.

Por fim, no caso de aprovação de Proposta de PIC, dar-se-á início à execução da segunda fase do PEPIC proposto, ou seja, a Fase de Preparação Teórica. Em caso de reprovação, o Orientador deve fazer registro conforme o Quadro 2, em seu Item 16.

\subsubsection{Segunda fase - Preparação Teórica}

Nesta fase, tem-se início o trabalho de pesquisa propriamente dito que será realizado pelo aluno sob a supervisão de seu orientador. A formação teórica que abrange essa fase tem por objetivo retratar o projeto de pesquisa de forma integral, no entanto, envolvendo, apenas, a porção teórica do proposto pelo aluno.

Ressalta-se que, tanto nessa fase como na subsequente, Fase Desenvolvimento Prático, a dinâmica de execução depende, intrinsecamente, do objeto de estudo que se reveste o PIC, podendo haver pequenas variações com respeito ao processo aqui apresentado. Entretanto, pela prática realizada em projetos anteriores nas IES consultadas neste estudo, a grande maioria dos PICs encaixa-se, adequadamente, nesta proposta de processo. A Figura 6 apresenta as atividades envolvidas nessa fase do PIC, os atores envolvidos e o fluxo de trabalho a ser executado. 
Figura 6: Atividades relacionadas à 2a fase do PEPIC - Preparação Teórica

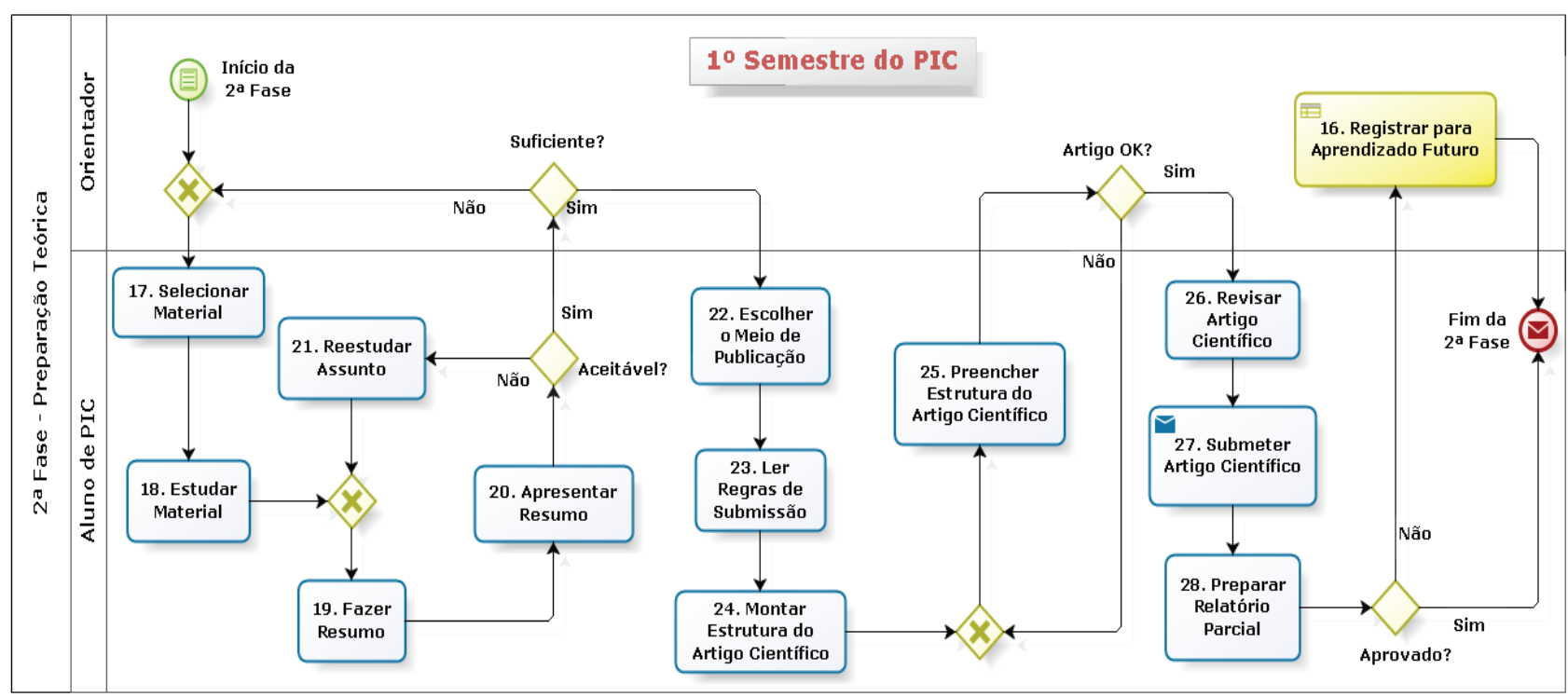

Fonte: os autores.

Há dois momentos fundamentais nesta fase, que se caracterizam, distintamente, como módulos-chave de atividades executadas de forma cíclica, sob a supervisão do Orientador, e que conduzem ao êxito desta fase: Módulo Construção do Conhecimento e Módulo Construção de Artigo Científico Teórico.

O Módulo Construção do Conhecimento é composto pelas atividades de 17 a 21, apresentadas no modelo da Figura 6, e se destina à construção progressiva do conhecimento teórico do aluno, com base no estudo dos ACs selecionados por ele. Já o Módulo Construção de Artigo Científico Teórico é composto pelas atividades de 22 a 27, apresentadas na Figura 6, e se destina à constru- ção de AC com base nos conhecimentos adquiridos no módulo anterior. Esse AC construído deve ser submetido à publicação em revista científica. Dependendo da capacidade do Aluno de PIC, há situações em que conseguem produzir até dois ou mais ACs.

Finalmente, O Quadro 3 apresenta os objetivos de cada uma das atividades e as peculiaridades que devem ser consideradas na execução dessa fase. Os números indicados no quadro referem-se às atividades apresentadas no modelo da Figura 6. O marco dessa fase, que também é o produto de trabalho tangível que pode ser apresentado à comunidade científica, seja interna ou externamente à IES, é a publicação do AC proveniente do estudo teórico.

Quadro 3: Caracterização das atividades da fase de Preparação Teórica. Fonte: os autores

\begin{tabular}{|c|c|}
\hline № & Objetivos e Peculiaridades \\
\hline 17 & $\begin{array}{l}\text { Objetivos: Realizar buscas de livros e de AC, em sites especializados, ou de revistas científicas visando criar acervo para estudo do referencial teórico necessário à pesquisa do PIC. } \\
\text { Peculiaridades: } 0 \text { Orientador deve apresentar aos alunos alguns recursos para se obter AC de qualidade para a pesquisa, como sugestão: a) consultas de obras literárias em bibliote- } \\
\text { cas; b) pesquisa de material em sites como o (iteSeerX e ScienceDirect; c) busca de revistas científicas por meio do WebQualis da (APES; e d) busca de material no Google Acadêmico. } \\
\text { A coleta do material poderá ficar a cargo do Orientador, que repassará a seus orientandos ou ficar a cargo do Aluno de PIC. A segunda opção dará maior liberdade e flexibilidade ao } \\
\text { Aluno de PIC em sua pesquisa. }\end{array}$ \\
\hline 18 & $\begin{array}{l}\text { Objetivos: Conhecer melhor } 0 \text { assunto ao estudar livros e AC coletados. } \\
\text { Peculiaridades: Os ACs devem ser estudados, pelo Aluno, de forma sequencial. } 0 \text { estudo de cada AC deve consumir em torno de } 15 \text { horas, das } 20 \text { h/semanais disponibilizadas pelo } \\
\text { Aluno para dedicar-se ao PIC. }\end{array}$ \\
\hline 19 & $\begin{array}{l}\text { Objetivos: Registrar pontos de interesse para a pesquisa ao fazer fichamento ou resumo de todos os AC estudados. Preparar uma apresentação em PowerPoint para os AC estudados. } \\
\text { Peculiaridades: } 0 \text { resumo deverá ter, no máximo, uma página contendo ideias relevantes e que sejam úteis ao projeto. A apresentação em PowerPoint deverá contendo, no máximo, } \\
20 \text { slides. Os resumos formarão o referencial teórico a ser utilizado em etapas posteriores. }\end{array}$ \\
\hline 20 & $\begin{array}{l}\text { Objetivos: Apresentar formalmente ao Orientador o assunto estudado para que ele faça uma apreciação quanto à pertinência ao objetivo do projeto do Aluno e direcione sugestões } \\
\text { visando maior esclarecimento de pontos eventuais confusos ou imprecisos. } \\
\text { Peculiaridades: Agendar com o Orientador data/hora e local. A apresentação dever ser em até } 20 \text { minutos. }\end{array}$ \\
\hline 21 & $\begin{array}{l}\text { Objetivos: Reestudar } 0 \text { AC buscando identificar soluções para os ajustes solicitados pelo Orientador. Refinar o resumo de forma que as ideias fiquem mais claras. } \\
\text { Peculiaridades: Essa atividade é realizada caso a apresentação do conteúdo estudado no AC pelo aluno necessite de correçôes ou complementações. Depois de realizadas as correções } \\
\text { deve executar o que prevê a atividade 20, anterior. }\end{array}$ \\
\hline
\end{tabular}




\begin{tabular}{|c|c|}
\hline 22 & $\begin{array}{l}\text { Objetivos: Fazer buscas por revistas científicas às quais a proposta de pesquisa se alinha e definir qual revista científica submeterá seu AC a ser construído posteriormente. } \\
\text { Peculiaridades: Após o estudo de certo número de AC, normalmente em torno de } 15,0 \text { Orientador sugere ao Aluno de PIC que procure uma revista científica, por meio do WebQualis, } \\
\text { a qual seu tema de projeto se adéque. Na oportunidade, o Orientador sugere qual nível da revista deverá ser procurada, se A, B ou C. Isso depende da qualidade técnica do estudo e da } \\
\text { evolução nas apresentações do Aluno de PIC. }\end{array}$ \\
\hline 23 & $\begin{array}{l}\text { Objetivos: Fazer seu cadastramento no site da revista selecionada. Fazer o download das regras de submissão e de possíveis modelos de artigos de submissão. Fazer uma leitura } \\
\text { minuciosa das regras de submissão, particularmente quanto à estrutura mínima exigida, regras de construção, prazos e outras informações pertinentes. } \\
\text { Peculiaridades: } 0 \text { conhecimento das regras auxilia o aluno na montagem da estrutura que deverá ter seu futuro AC. Éútil fazer o download de modelos de arquivos pré-formatados } \\
\text { para servir como guia na construção do AC do Aluno. }\end{array}$ \\
\hline 24 & $\begin{array}{l}\text { Objetivos: Fazer a montagem do esqueleto do AC a ser criado, contemplando todas as Seções exigidas pelas regras de construção da revista científica selecionada e apresentar ao } \\
\text { Orientador. } \\
\text { Peculiaridades: Nesse momento, o Aluno tem condições de criar o esqueleto de seu AC e apresentá-lo a seu Orientador para sugerir ideias quanto à estrutura do AC a ser criado. }\end{array}$ \\
\hline 25 & $\begin{array}{l}\text { Objetivos: Inserir informações nas diversas Seções do AC com ideias progressivas que conduzam ao objetivo traçado para o AC para ficar em condições de ser submetido à revista } \\
\text { científica escolhida. } \\
\text { Peculiaridades: Essa atividade tem duração de, aproximadamente, dois meses para ser concluída, fruto de experiências em trabalhos anteriores. Há uma grande interação entre Aluno } \\
\text { e Orientador até que o AC fique em boas condiççes de ser submetido à revista científica selecionada. }\end{array}$ \\
\hline 26 & $\begin{array}{l}\text { Objetivos: Fazer ajustes finais, sugerido pelo Orientador. Verificar se o AC criado pelo Aluno atende a todas as regras de submissão previstas na revista científica selecionada. Isso } \\
\text { minimizar riscos de não aprovaçãoo ou ressalvas. } \\
\text { Peculiaridades: Tal ajuste refere-se à busca de conformidade do AC criado com: a forma, as normas de construção e as regras de português do texto. }\end{array}$ \\
\hline 27 & $\begin{array}{l}\text { Objetivos: Submeter o AC e monitorar andamento para publicação em revista científica contro-lando: resposta do editor quanto a possíveis ajustes a serem feitos, aprovação ou } \\
\text { reprovação de publicação. } \\
\text { Peculiaridades: } 0 \text { aluno deve dar ciência a seu Orientador } 0 \text { andamento dessa atividade. }\end{array}$ \\
\hline 28 & $\begin{array}{l}\text { Objetivos: Preencher o relatório parcial contendo: identificação do projeto e envolvidos; aç̃oes realizadas; produtos gerados; dificuldades; sugestões; direcionamentos para solução de } \\
\text { problemas ocorridos; e impasses não solucionados. Entregar o relatório à Coordenação de projetos PIC. } \\
\text { Peculiaridades: } 0 \text { Aluno auxilia o Orientador nessa atividade com informações vivenciadas por ele. } 0 \text { Orientador faz ajustes e insere outras observaçōes collidas ao longo do semestre } \\
\text { e emite parecer se o Aluno está ou não aprovado para prosseguir na terceira fase do PIC. }\end{array}$ \\
\hline
\end{tabular}

\subsubsection{Terceira fase - Desenvolvimento Prático}

Nesta fase, o aluno pesquisador tem a possibilidade de pôr em prática o que delineou, inicialmente, na Fase de Preparação Teórica. Trata-se de uma fase em que o uso de ferramentas CASE, hardware, experimentos, algoritmos, software especialistas, criação de software específicos, dentre outros, tornam-se a matéria-prima das ações a serem executadas.

Ressalta-se que essa fase pode, facilmente, ser adaptada aos procedimentos das IES que vierem a implantar o PEPIC proposto, ou mesmo para adequar-se à abordagem dos Orientadores. De qualquer maneira, o processo aqui proposto já conduz a uma prática que atende, em boas condições, tanto ao Aluno de PIC como ao Orientador na execução e controle do projeto. A Figura 7 apresenta as atividades envolvidas nessa fase do PIC, os atores envolvidos e o fluxo de trabalho a ser executado.

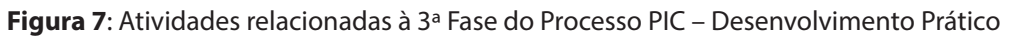

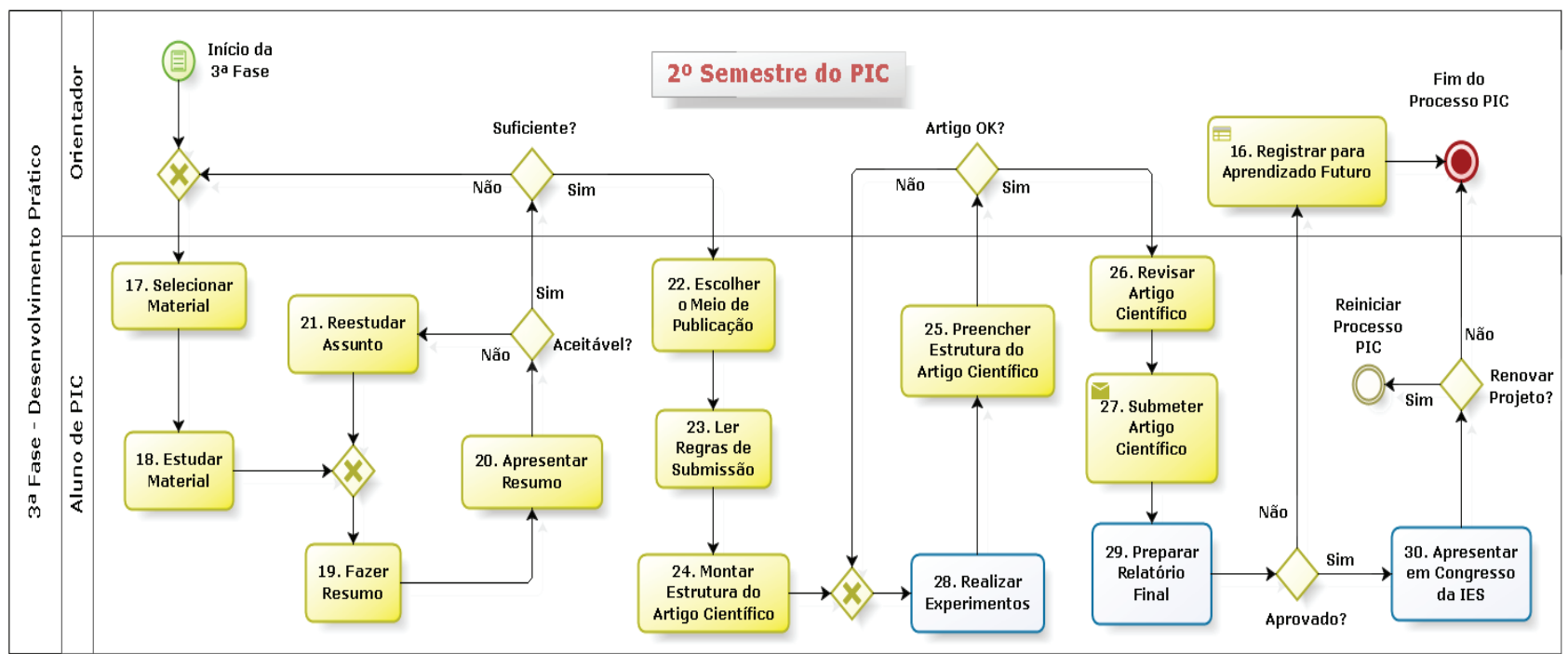

Fonte: os autores 
O Quadro 4 apresenta as características de cada uma das atividades desta fase. Os números indicados referem-se às atividades apresentadas no modelo da Figura 7. As atividades assinaladas na Figura 7 em cor amarela, ou seja, as atividades de 16 a 27, são similares àquelas existentes na Fase Preparação Teórica.

Quadro 4: Caracterização das atividades da fase de Desenvolvimento Prático. Fonte: os autores

\begin{tabular}{|c|c|}
\hline № & Objetivo \\
\hline 28 & $\begin{array}{l}\text { Objetivos: Aplicar na prática os fundamentos teóricos obtidos na fase de } \\
\text { Preparação Teórica ao realizar experimentos, com base no que se propõe o } \\
\text { projeto, utilizando-se de ferramentas, soft-wares especialistas ou qualquer } \\
\text { outro recurso que conduza à prática da teoria formulada para a geração de } \\
\text { um produto técnico. } \\
\text { Peculiaridades: Essa atividade é o diferencial nessa fase do projeto PIC, pois é } \\
\text { a oportunidade de o aluno pôr em prática todos os conhecimentos adquiridos } \\
\text { e que dará visibilidade real de sua contri-buição, perante a sociedade, de sua } \\
\text { produção científica. A seleção correta e emprego adequado de ferramentas } \\
\text { que permitam a experimentação é o que conduzirá a uma solução prática e } \\
\text { possí-vel de ser aplicada futuramente. }\end{array}$ \\
\hline 29 & $\begin{array}{l}\text { Objetivos: Preencher o relatório final com: identificação do projeto e } \\
\text { envolvidos; açōes realizadas; produtos gerados; dificuldades; sugestões; } \\
\text { direcionamentos para solução de problemas ocorridos; impasses não solucio- } \\
\text { nados; além de outros, a critério do Orientador e/ou instituição e entregar à } \\
\text { Coordenação de PIC da IES. } \\
\text { Peculiaridades: Esse documento servirá para fomentar uma possivel renova- } \\
\text { ção do projeto PIC, perante a IES, caso o aluno e Orientador assim desejarem. } \\
\text { Seu conteúdo deve apresentar, objetivamente, a importância e o trabalho } \\
\text { desenvolvido ao longo de todo o PIC. }\end{array}$ \\
\hline 30 & $\begin{array}{l}\text { Objetivos: Divulgar, no meio acadêmico, o trabalho de PIC realizado por meio } \\
\text { de apresentações en volvendo o estudo e prática realizada na } 2^{\mathrm{a}} \mathrm{e} 3^{\mathrm{a}} \text { fase do } \\
\text { PIC, respectivamente. Dispor os conceitos e técnicas empregadas e revelar os } \\
\text { resultados obtidos com o PIC desenvolvido. } \\
\text { Peculiaridades: Essa atividade deve ser preparada e realizada com esmero, } \\
\text { pois possibilitar externar ao público acadêmico o esforço e resultados } \\
\text { alcançados pelo PIC. }\end{array}$ \\
\hline
\end{tabular}

Fonte: Dos Autores

\subsection{Implantação do PEPIC em IES privada}

Para a implantação do PEPIC proposto na IES, sugere-se a execução de duas etapas distintas: Projeto Piloto e Implantação Institucional. Essas etapas são explicadas e detalhadas nas subseções a seguir.

\subsubsection{Projeto piloto}

O processo é aplicado em um grupo reduzido de
PICs. Por exemplo: supondo que a IES possua 2 cursos na área de tecnologia e a demanda total de PIC deles seja 15 projetos. Sugere-se, então, eleger 2 ou 3 desses projetos, de cada curso para atuarem no projeto-piloto de implantação. É desejável que tais PIC selecionados sejam de diferentes orientadores para dar mais lisura na obtenção dos resultados. Ainda, como sugestão, a escolha dos orientadores deve recair naqueles que possuam mais experiência, pois terão mais condições de criticarem, amiúde, cada fase do processo a ser executado.

Deve-se considerar, ainda, como fator primordial, para o êxito na implantação do PEPIC proposto, a escolha de professores-orientadores que sejam favoráveis a mudanças e que entendam o processo proposto como um mecanismo que agregará valor à execução dos projetos de IC na IES. Assim, o objetivo do Projeto Piloto é executar todo o processo, observar e registrar, em cada atividade desenvolvida, eventuais dificuldades e/ou problemas para, em seguida, os orientadores envolvidos sugerirem adaptações pertinentes.

Por fim, é aconselhável que o Coordenador do Projeto Piloto promova reuniões, ao longo de sua execução, de forma que todos orientadores participantes tenham a oportunidade de externar suas observações para que se chegue a um consenso de quais medidas devem ser consideradas na implantação do processo proposto.

\subsubsection{Implantação institucional}

A etapa de implantação pode ser realizada de duas maneiras: em paralelo ao Projeto-Piloto ou após a conclusão do Projeto-Piloto. A primeira opção é concluída em 2 anos e meio. Essa é a opção mais indicada. O assinalado na Figura 8, em cor vermelha, refere-se ao Projeto Piloto e, em azul, à Implantação Institucional. Essa estratégia, porém, exige certa coordenação para que: a) as etapas de implantação não interfiram umas nas outras; e b) o aprendizado obtido em cada fase do Projeto Piloto seja replicado, oportunamente, para cada fase de Implantação Institucional. 
Figura 8: Implantação do processo PIC em IES.

\section{Implantação do Processo PIC em IES}
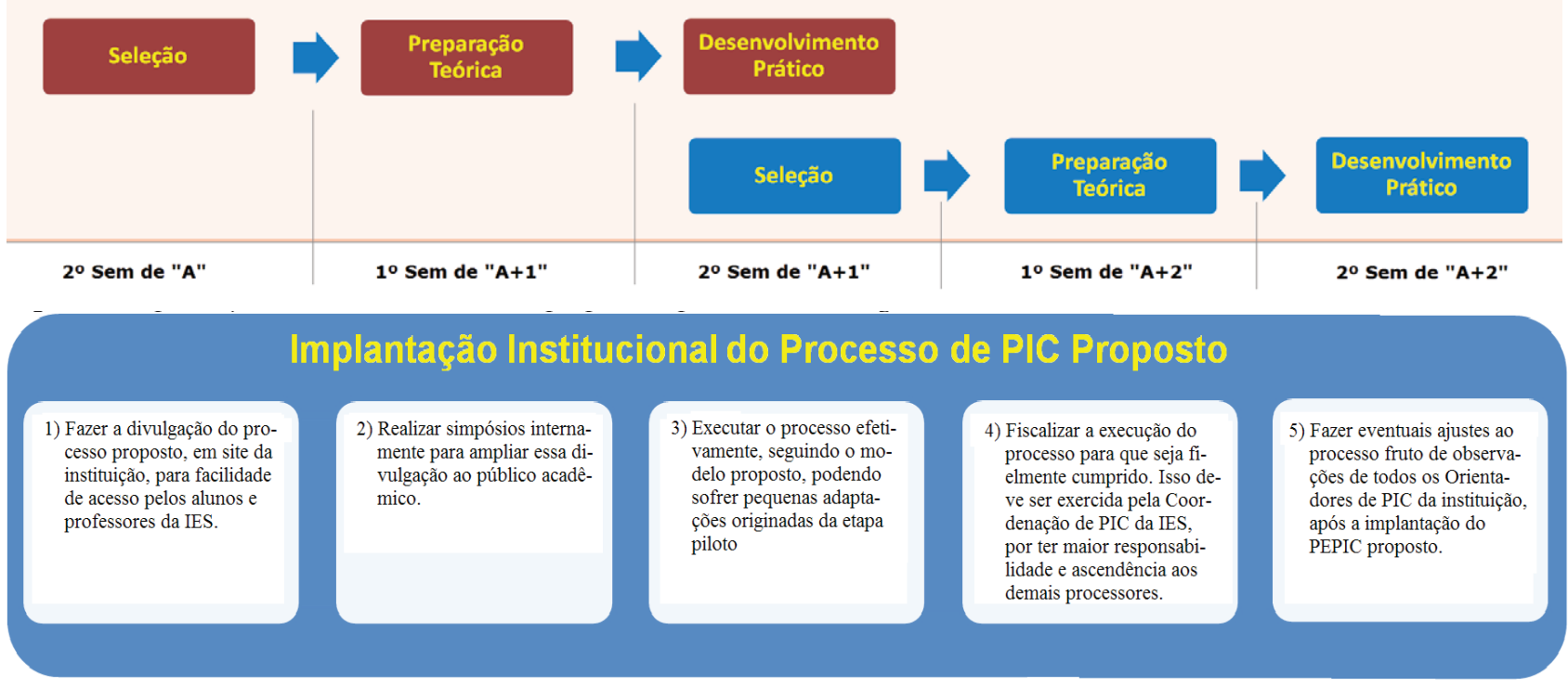

Fonte: os autores.

\section{Conclusões e Trabalhos Futuros}

O objetivo deste estudo foi disponibilizar uma proposta de PEPIC, de forma detalhada e de fácil adoção pelas IES privadas, além de servir como um instrumento padronizado para se executar um PIC de forma efetiva. Destacaram-se, em especial, aspectos de relação humana entre alunos de PIC e seus orientadores.

As principais vantagens de se adotar o PEPIC proposto na instituição são: padronização de procedimentos; facilidade de entendimento das diversas fases que o engloba; facilidade em se administrar os projetos em andamento; facilidade de sua implantação institucional; facilidade de seu manuseio ao servir como instrumento facilitador aos envolvidos; e, por fim, incremento na qualidade dos PIC a serem desenvolvidos nesse modelo.

Apontam-se, como estudos e ações futuras, a implantação e o monitoramento do PEPIC proposto em IES privadas para se colherem sugestões de melhorias, visando, precipuamente, ao seu aprimoramento.

\section{Referências}

BRASIL. Ministério da Educação. [Homepage]. Disponível em: <http://portal.mec.gov.br>. Acesso em: 05 ago. 2015b.
CARTONI, Daniela Maria. Construindo o Projeto de Pesquisa. Anuário da Produção Acadêmica Docente, Valinhos, v. 3, n. 5, p. 47-60, 2009 b.

CARTONI, Daniela Maria. Pesquisa científica: planejando etapas ao longo do tempo. Anhanguera Educacional S.A. Anuário da Produção Acadêmica Docente, Valinhos, v. 3, n. 6, p. 9-24, 2009a.

\section{CONSELHO NACIONAL DE DESENVOLVIMENTO} CIENTÍFICO E TECNOLÓGICO (CNPq). [Homepage]. Disponível em: <http://www.cnpq.br/>. Acesso: ago. 2015a.

COSTA. O processo de formação de pesquisadores: análise do programa de iniciação científica da Universidade Federal de Santa Catarina no período de 1990 a 2012. 2013. Dissertação (Mestrado) - Programa de Pós-Graduação em Ciência da Informação, Universidade Federal de Santa Catarina, Centro de Ciências da Educação, Florianópolis, 2013.

\section{FUNDAÇÃO DE AMPARO À PESQUISA DO ESTADO} DE SÃO PAULO. Código de boas práticas científicas. 2012. Disponível em: <http://fapesp.br>. Acesso em: 05 jan. 2016.

FUNGHETTO, Suzana Schwerz; FONSECA, Dirce Mendes da. Pesquisa e ação pedagógica: concepção e prática da Iniciação Científica. Univ. Hum., Brasília, v. 5, n. 1/2, p. 1-13, jan./dez. 2008. 
GAMBOA, Silvio Sánchez. As condições da produção científica em educação: do modelo de áreas de concentração aos desafios das linhas de pesquisa. Educação Temática Digital - EDT, Campinas, v. 4, n. 2, p.78-93, jun. 2003.

GATES, Ann Q. et al. Meeting the challenge of expanding participation in the undergraduate research experience. Proceedings of the 30th Frontiers in Engineering Conference, p. 1133-1138, Phoenix, AZ. 1998.

LORDELO, José Albertino Carvalho et al. Pesquisa e formação: a iniciação científica na graduação como preditora da continuidade da formação pós-graduada stricto sensu. R. FACED, Salvador, n. 20, p. 9-34, jul./dez. 2011.

MACCARIELLO, Maria do Carmo Moreira Martins et al. Ação pedagógica na iniciação científica. 2. ed. São Paulo: 2002.

MANZINI, Eduardo José. Entrevista semi estruturada: análise de objetivos e de roteiros. Departamento de Educação Especial, Programa de Pós-Graduação em Educação, UNESP, Marília-SP, Apoio: CNPq. Disponível em: <http://www.sepq.org.br/IIsipeq/anais/pdf/gt3/04.pdf >. Acesso em: 05 nov. 2015.

MARCUSCHI, Luiz Antônio. Avaliação do programa institucional de bolsas de iniciação científica (PIBIC) do $C N P q$ e propostas de ação: relatório versão final. Recife: UFPE, 1996.

MASSI, Luciana; QUEIROZ, Salete Linhares. Estudos sobre iniciação científica no Brasil: uma revisão. Cadernos de Pesquisa, São Paulo, v. 40, n. 139, p. 173-197, jan./abr. 2010.

MAZON, Luciano; TREVIZAN, Maria Auxiliadora. Fecundando o processo da interdisciplinaridade na iniciação científica. Revista Latino-Americana de Enfermagem, v. 9, n. 4, p. 83-87, 2001.
MORAES, Flavio Fava-de-; FAVA, Marcelo. A iniciação científica: muitas vantagens e poucos riscos. São Paulo em Perspectiva, v. 14, n. 1, p. 73-77, 2000.

NEUENFELDT, Derli Juliano et al. Iniciação à pesquisa no ensino superior: desafios dos docentes no ensino dos primeiros passos. Ciência \& Educação, Bauru, v. 17, n. 2, p. 289-300, 2011.

OBJECT MANAGEMENT GROUP. Business Process Model and Notation (BPMN) Version 2.0. Disponível em: <http://www.omg.org/spec/BPMN/2.0/PDF>. Acesso em: 05 jul. 2015.

OLIVEIRA, L. C. V. Iniciação à pesquisa no ensino superior: o novo e o velho espírito científico nas atividades acadêmicas. In: REUNIÃO ANUAL DA ANPED, 24., 2001, Caxambu. Anais... Caxambu, 2001. p. 1-15. Disponível em: <http://www.anped.org.br/reunioes/24/ T1181081976681.doc>. Acesso em: 05 jul. 2014.

SILVA JUNIOR, Manoelito Ferreira et al. Iniciação científica: percepção do interesse de acadêmicos de odontologia de uma universidade brasileira. Saúde Soc. São Paulo, v. 23, n. 1, p. 325-335, 2014.

SOUSA, João Marques Teixeira de; MARQUES, Herberth Vera Cruz Furtado. Contribuições da iniciação científica no processo de ensino e aprendizagem em química. Cadernos de Pesquisa, São Luís, v. 18, n. 3, set./dez. 2011.

VILAN FILHO, Jayme Leiro et al. A orientação acadêmica nos artigos em autoria múltipla de periódicos científicos das áreas de informação. ENCONTRO NACIONAL DE PESQUISA EM CIÊNCIA DA INFORMAÇÃO (ENANCIB), 12., 2011, Brasília, Anais... Brasília, 2011. 23 a 26 out. 2011.

WIKIPÉDIA. [Homepage]. Disponível em: <https:// pt.wikipedia.org/wiki/Método_indutivo>. Acesso em: 05 ago. 2015. 